\title{
Nicotine induces cell proliferation by $\beta$-arrestin-mediated activation of Src and Rb-Raf-1 pathways
}

\author{
Piyali Dasgupta, Shipra Rastogi, Smitha Pillai, Dalia Ordonez-Ercan, \\ Mark Morris, Eric Haura, and Srikumar Chellappan
}

Department of Interdisciplinary Oncology, H. Lee Moffitt Cancer Center and Research Institute, University of South Florida, Tampa, Florida, USA.

\begin{abstract}
Recent studies have shown that nicotine, a component of cigarette smoke, can stimulate the proliferation of non-neuronal cells. While nicotine is not carcinogenic by itself, it has been shown to induce cell proliferation and angiogenesis. Here we find that mitogenic effects of nicotine in non-small cell lung cancers (NSCLCs) are analogous to those of growth factors and involve activation of Src, induction of Rb-Raf-1 interaction, and phosphorylation of Rb. Analysis of human NSCLC tumors show enhanced levels of Rb-Raf- 1 complexes compared with adjacent normal tissue. The mitogenic effects of nicotine were mediated via the $\alpha_{7}$-nAChR subunit and resulted in enhanced recruitment of E2F1 and Raf-1 on proliferative promoters in NSCLC cell lines and human lung tumors. Nicotine stimulation of NSCLC cells caused dissociation of Rb from these promoters. Proliferative signaling via nicotinic acetylcholine receptors (nAChRs) required the scaffolding protein $\beta$-arrestin; ablation of $\beta$-arrestin or disruption of the Rb-Raf-1 interaction blocked nicotine-induced proliferation of NSCLCs. Additionally, suppression of $\beta$-arrestin also blocked activation of Src, suppressed levels of phosphorylated ERK, and abrogated $\mathrm{Rb}-\mathrm{Raf}-1$ binding in response to nicotine. It appears that nicotine induces cell proliferation by $\beta$-arrestin-mediated activation of the Src and Rb-Raf-1 pathways.
\end{abstract}

\section{Introduction}

Tobacco smoke contains a variety of tobacco-specific carcinogens, many of which are derivatives of nicotine that are formed during the curing of tobacco (1). These include molecules like 4-(methylnitrosamino)-1-(3-pyridyl)-1-butanone (NNK) and $\mathrm{N}^{\prime}$-nitrosonornicotine (NNN) (2). Nicotine itself exerts its cellular functions through nicotinic acetylcholine receptors (nAChRs), which are widespread in neurons and neuromuscular junctions (3). Studies in recent years have shown that $\mathrm{nAChRs}$ are also present in a variety of non-neuronal tissues, including human bronchial epithelial cells, human endothelial cells, and astrocytes (4-6). These observations suggested that signaling through the $\mathrm{nAChRs}$ could have functional roles in non-neuronal cells as well (7). Further, it appears likely that the pathological role of nicotine in human diseases is mediated, at least in part, through its direct effects on non-neuronal cells $(6,8)$.

The finding that $\mathrm{nAChR}$ are present on non-neuronal cells was followed by the observation that nicotine could induce the proliferation of endothelial cells $(4,9)$. Further, it was found that nicotine and structurally related carcinogens like NNK could induce the proliferation of a variety of small cell lung carcinoma cell lines $(10-12)$. This led to the hypothesis that nicotine and other tobacco carcinogens might be playing a direct role in the induction and progression of human lung cancers $(4,5,13)$. While there is no evidence that nicotine contributes to the induction of tumors,

Nonstandard abbreviations used: ChIP, chromatin IP; DH $\beta E$, dihydro $\beta$-erythoidine; EGM, endothelial growth medium; GPCR, G protein-coupled receptor; HAEC, human aortic endothelial cell; HMEC-L, human microvascular endothelial cell from lung; MAA, methylallyl aconitine; MEK, MAPK kinase; $\mathrm{nAChR}$, nicotinic acetylcholine receptor; NHBE, normal human bronchial epithelial cell; NNK, 4-(methylnitrosamino)-1-(3-pyridyl)-1-butanone; NNN, N'-nitrosonornicotine; NSCLC, non-small cell lung cancer; SAEC, small airway epithelial cell.

Conflict of interest: The authors have declared that no conflict of interest exists. Citation for this article: J. Clin. Invest. 116:2208-2217 (2006). doi:10.1172/JCI28164. it has been demonstrated that nicotine promotes the growth of solid tumors in vivo, suggesting that nicotine might be contributing to the progression of tumors already initiated $(4,14)$. Indeed, studies by Song et al. have shown that nAChRs expressed on lung carcinoma form a part of an autocrine-proliferative network that facilitates the growth of neoplastic cells $(13,15)$; other studies have demonstrated that nicotine can promote the growth of colon, gastric, and lung cancers $(4,5,13,16,17)$.

It has been found that in non-neuronal tissues nicotine induces the secretion of growth factors like bFGF, TGF- $\alpha$, VEGF, and PDGF (18), upregulation of the calpain family of proteins (19) as well as COX-2 and VEGFR-2 (20), causing the eventual activation of Raf/MAPK kinase/ERK (Raf/MEK/ERK) pathway (21, 22). Since nAChRs do not have intrinsic tyrosine kinase activity (3), the molecular mechanisms underlying the proliferative signaling remain unclear. Here we demonstrate that nicotine-mediated induction of cell proliferation involves recruitment of $\beta$-arrestin to the receptor, which facilitates the activation of Src; this in turn leads to the binding of Raf-1 kinase to Rb, leading to cell cycle entry. IP/Western blot analysis of human non-small cell lung cancer (NSCLC) tumor tissues showed elevated Rb-Raf-1 complexes in tumors relative to adjacent normal lung tissue, suggesting that perhaps the Rb-Raf-1 pathway contributes to the genesis of these tumors. Further, chromatin IP (ChIP) analysis of human NSCLC tumor samples demonstrated increased recruitment of E2F1 and Raf-1 to proliferative promoters like $c d c 6$ and $c d c 25 A$. Our results suggest that binding of $\beta$-arrestin to nAChRs is an early and critical event in the initiation of nicotineinduced mitogenesis; the subsequent steps resemble growth factorinduced cell proliferation, including activation of Src, association of $\mathrm{Rb}$ to Raf-1, inactivation of $\mathrm{Rb}$, and enhanced recruitment of E2F1 and Raf-1 to proliferative promoters. These events can be expected to contribute to the growth and progression of tumors exposed to nicotine through tobacco smoke or cigarette substitutes. 
A

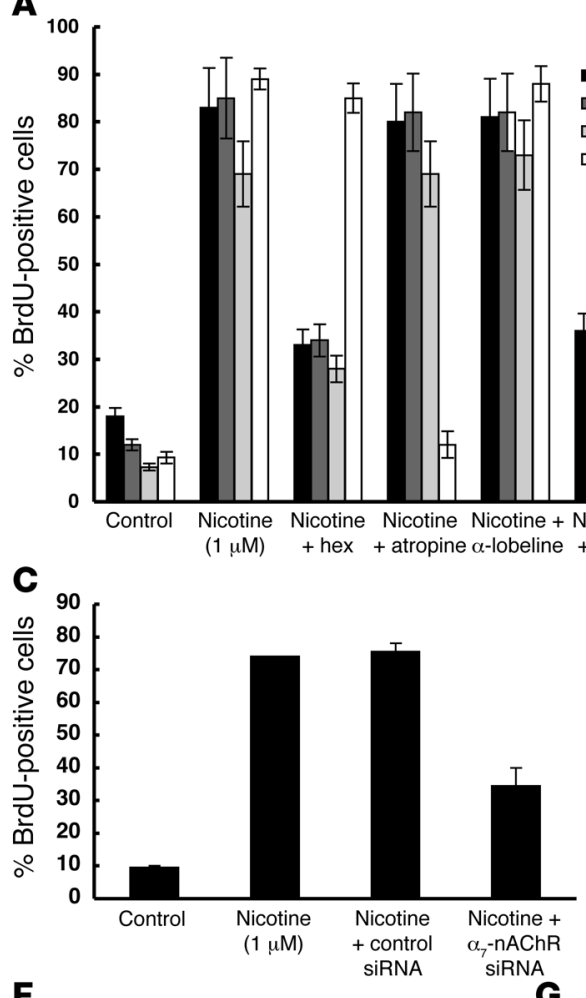

$\mathbf{F}$

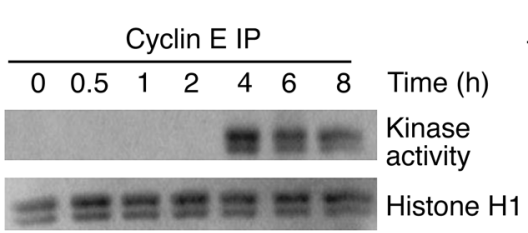

B

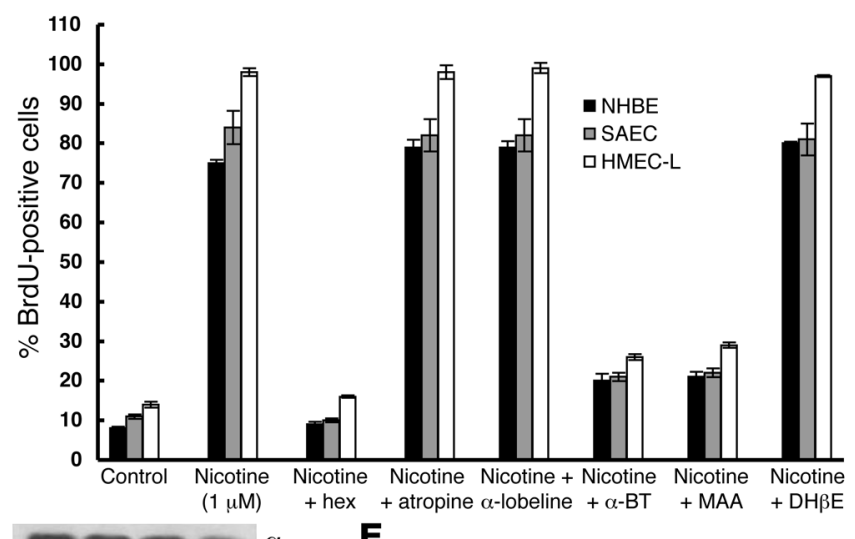

$=-\alpha_{7} \quad \mathbf{E}$

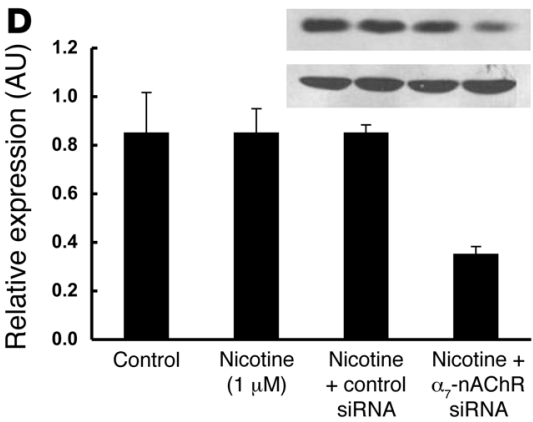

Actin

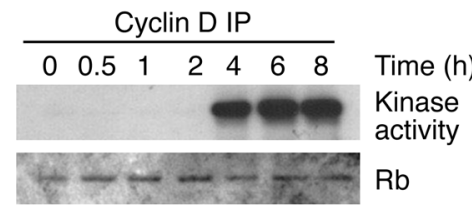

H

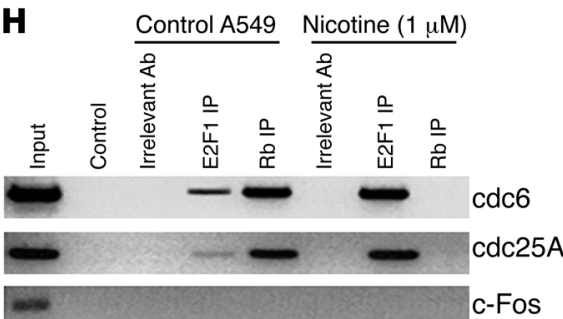

Figure 1

Nicotine induces Rb inactivation and S-phase entry in lung cells. (A) Nicotine induces S-phase entry. Quiescent H23, H441, H226, and A549 cells were treated with $1 \mu \mathrm{M}$ nicotine for 18 hours in the presence or absence of a panel of nAChR subunit inhibitors. hex, hexamethonium bromide; $\alpha$-BT, $\alpha$-bungarotoxin. (B) A similar experiment was performed using normal lung cells, namely NHBEs, SAECs, and HMEC-Ls. (C) Transfection of $\alpha_{7}$-nAChR siRNA ablated the mitogenic activity of nicotine on A549 cells, whereas a nontargeting control siRNA had no effect. (D) Western blotting analysis showed that $\alpha_{7}$-nAChR siRNA ablated the expression of $\alpha_{7}$-nAChR in A549 cells, which was quantitated using densitometric analysis. A nontargeting siRNA sequence was used as a control for all experiments. (E) An in vitro assay using full-length Rb as a substrate to measure cyclin D-associated kinase activity in quiescent and nicotine-stimulated A549 cells. The lower panel shows a Coomassie Blue staining of the gel indicating comparable amounts of substrate in all lanes. (F) A similar assay as in $\mathbf{E}$, showing cyclin $E$-associated kinase activity using histone $\mathrm{H} 1$ as a substrate. (G) Nicotine induces the dissociation of E2F1 from Rb in A549 cells, with concomitant phosphorylation of Rb. WB, Western blot. (H) Nicotine caused increased recruitment of E2F1 on the E2F-responsive cdc6 promoter and cdc25A accompanied by concomitant dissociation of Rb. PCR for the c-Fos promoter was taken as the negative control.

\section{Results}

Nicotine induces proliferation of NSCLCs via $\alpha_{7}-n A C h R s$. We examined the proliferative effects of nicotine in NSCLC cell lines A549 (human bronchoalveolar carcinoma), NCI-H23, NCI-H441 (lung adenocarcinoma), and NCI-H226 (pleural effusion squamous cell carcinoma) as well as on primary normal human bronchial epithelial cells (NHBEs), small airway epithelial cells (SAECs), human aortic endothelial cells (HAECs), and human microvascular endothelial cells from lung (HMEC-Ls). BrdU incorporation assays showed that $1 \mu \mathrm{M}$ nicotine, which is equivalent to the amount present in the bloodstream of those who smoke 1 pack a day, stimulated S-phase entry in all the aforementioned cells. Figure 1A shows that the level of BrdU incorporation in quiescent A549 cells was only $12 \% \pm 0.4 \%$; upon treatment with $1 \mu \mathrm{M}$ nicotine, $89 \% \pm 7.6 \%$ of the cells were found to be in S-phase. Similar results were obtained in the other NSCLC cells. The mitogenic effects of nicotine were abrogated by the general $\mathrm{nAChR}$ antagonist hexamethonium bromide but were unaffected by atropine, an antagonist of the closely related muscarinic receptor, showing that the proliferative effects of nicotine required $\mathrm{nAChR}$ function (Figure $1, \mathrm{~A}$ and $\mathrm{B}$ ). The stimulation of A549 and $\mathrm{H} 23$ cells with $1 \mu \mathrm{M}$ nicotine induced $89 \% \pm 7.6 \%$ and $83 \% \pm 7.1 \%$ of the cells into S-phase, respectively. When the cells were treated in the presence of hexamethonium the percentage of cells in S-phase dropped to $28 \% \pm 1.7 \%$ (in A549 cells) and $34 \% \pm 2.8 \%$ 
A

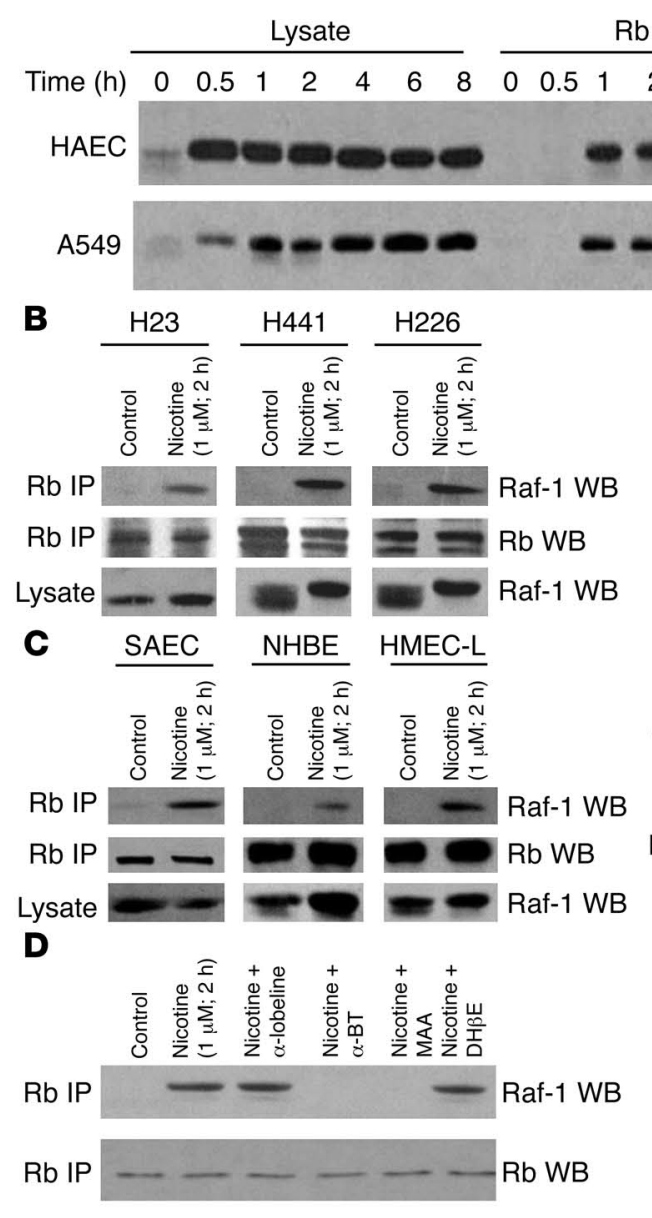

E

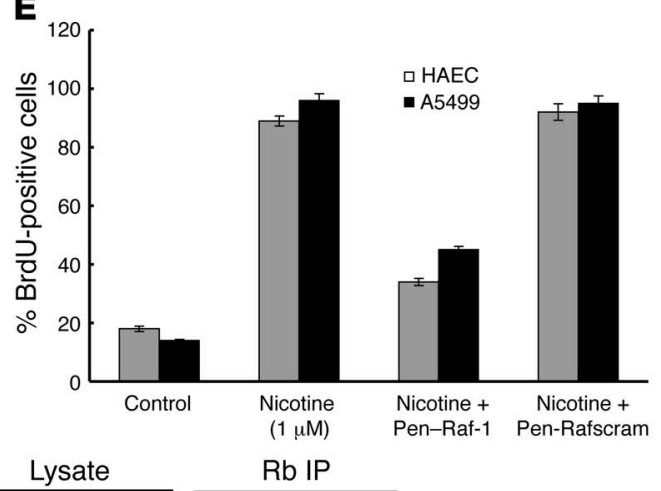

$\mathbf{F}$ Raf-1 WB Raf-1 WB

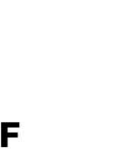

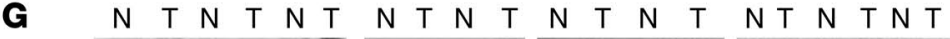

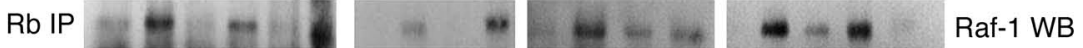

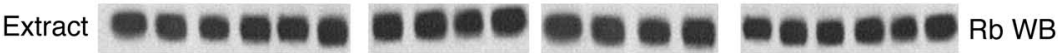

$\mathbf{H}$

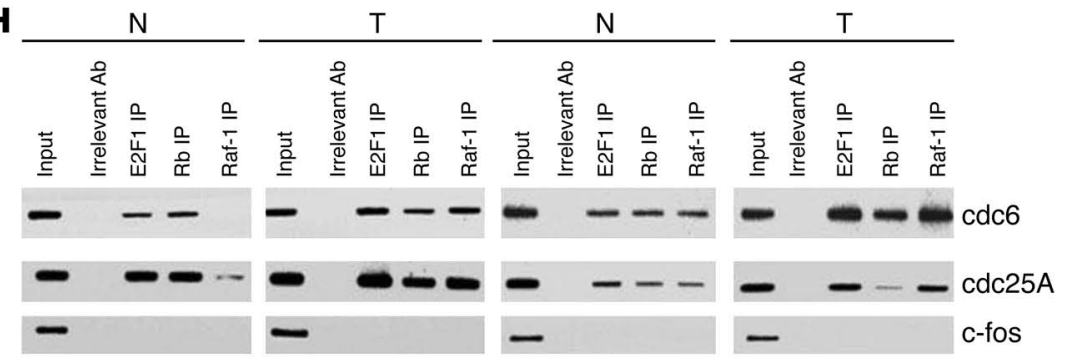

Figure 2

Rb-Raf-1 interaction is induced by nicotine in cultured cells and is elevated in tumor samples. (A) Nicotine induces the binding of Raf- 1 to Rb in HAEC and A549 cells as seen by IP/Western blotting. Rb-Raf-1 interaction was also observed in other NSCLC cell lines like H441, H226, and H23 (B) as well as in SAECs, NHBEs, and HMEC-Ls (C). (D) Nicotine-induced Rb-Raf-1 binding is mediated by $\alpha_{7}-n A C h R s$ in A549 cells. Quiescent A549 cells were stimulated with $1 \mu \mathrm{M}$ nicotine in the presence or absence of $1 \mu \mathrm{M}$ of the indicated antagonists; IP/Western blot shows the inhibition of the Rb-Raf- 1 interaction by $\alpha_{7}$-nAChRs inhibitors $\alpha$-bungarotoxin and MAA. (E) Penetratin-Raf- 1 (Pen-Raf-1) peptide conjugate abrogated nicotine-induced S-phase entry in A549 cells (black bars) and HAECs (gray bars) whereas a scrambled peptide conjugate, Pen-Rafscram, had no effect. (F) The penetratin-Raf-1 conjugate abolished Rb-Raf-1 binding in nicotine-stimulated A549 cells and HAECs, whereas the scrambled peptide conjugate (Pen-Rafscram) did not; Rb-Raf-1 interaction was measured by IP/Western blot. (G) NSCLC tumors (N) contained more Rb-Raf-1 complexes than adjacent normal tissue (T). Rb-Raf-1 interaction was assessed by IP/Western blot on nuclear extracts. (H) ChIP assays on human NSCLC tumor samples show that more Raf-1 was present on cdc6 and cdc25A promoters in tumor samples compared with adjacent normal lung tissues.

(in $\mathrm{H} 23$ cells). Further, nicotine-induced proliferation of A549, $\mathrm{H} 23, \mathrm{H} 441$, and $\mathrm{H} 226$ cells was significantly ablated by $2 \alpha_{7}$ subunit antagonists, $\alpha$-bungarotoxin and methylallyl aconitine (MAA), whereas it was unaffected by $\alpha$-lobeline ( $\alpha_{4} \beta_{2}$ subunit inhibitor) or dihydro $\beta$-erythoidine (DH $\beta E ; \alpha_{3} \beta_{2}$ and $\alpha_{4} \beta_{2}$ subunit inhibitor) (5), suggesting that $\alpha_{7}$ subunits primarily mediate the mitogenic effects of nicotine (Figure 1A). The BrdU assay graphs represent 2 independent experiments, each data point being in duplicate and representing 100 cells from 3 fields. Similar results were obtained in NHBEs and SAECs from normal lungs as well as HMEC-Ls (Figure $1 B)$. The role of $\alpha_{7}-n A C h R$ in the proliferative effects of nicotine was further verified by siRNA techniques (Figure 1, C and D). The densitometric analysis shown in Figure 1D is representative of 3 Western blotting experiments performed with independent sets of lysates. Nicotine stimulation of A549 cells transfected with $\alpha_{7}$-nAChR siRNA showed reduced S-phase entry relative to those transfected with control siRNA (Figure 1C), confirming the results with receptor antagonists.

Nicotine induces cyclin/cdk activity and Rb phosphorylation. The retinoblastoma protein plays a central role in regulating cell cycle progression, and the $\mathrm{Rb}$ gene is inactivated in a wide variety of cancers $(23,24)$. Inactivation of $R b$ by kinases associated with cyclins $D$ and $\mathrm{E}$ leads to the activation of E2F-regulated proliferative promoters, facilitating S-phase entry (24). The effect of nicotine stimulation on cyclin/cdk activity as well as Rb function was next examined. Toward this purpose, quiescent A549 cells were stimu- 

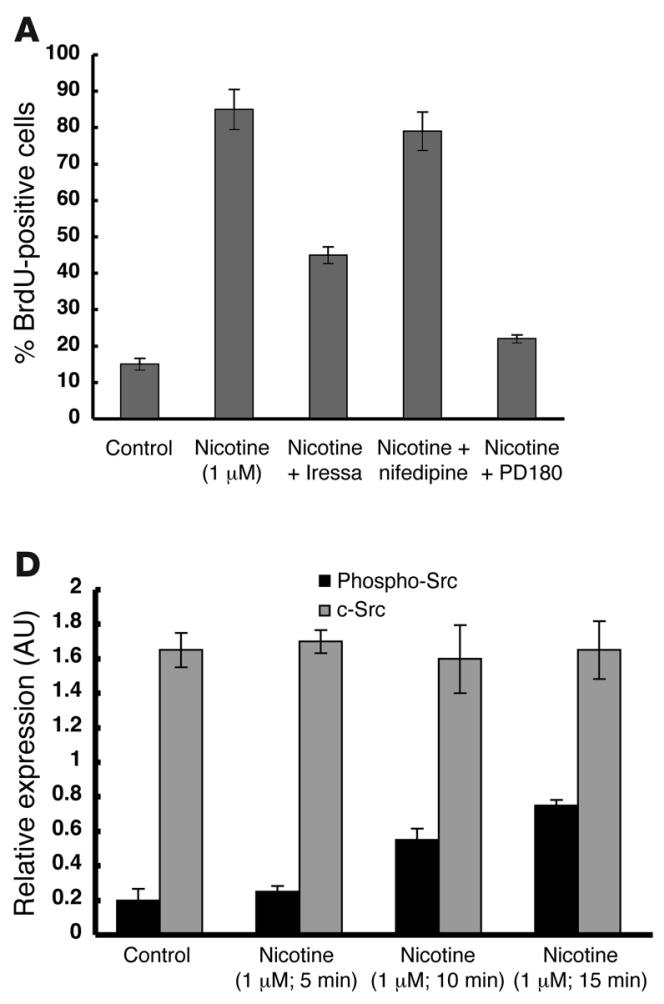

B

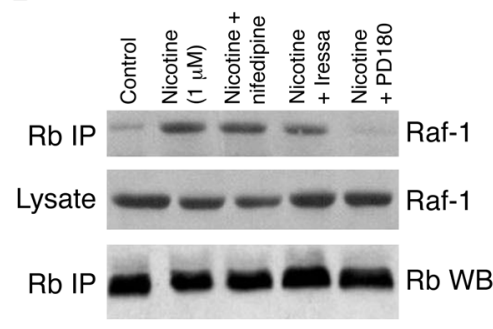

E

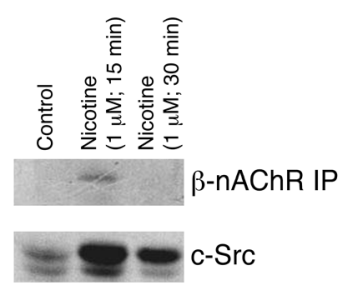

C

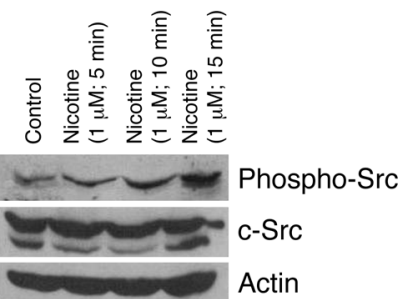

$\mathbf{F}$

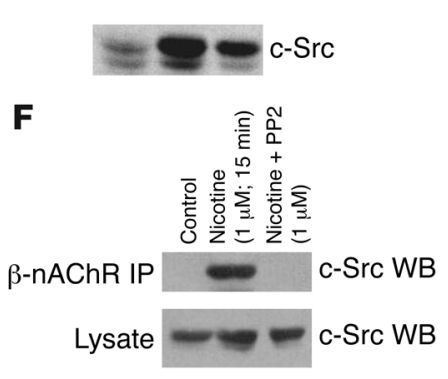

G

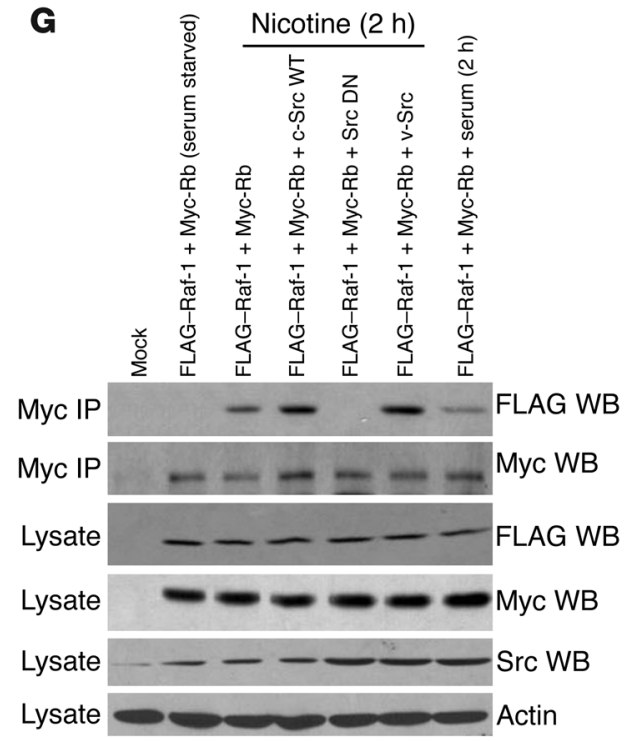

Figure 3

The mitogenic activity of nicotine requires Src. (A) Nicotine-induced cell proliferation was ablated by $1 \mu \mathrm{M}$ of the Src inhibitor PD180. The EGFR inhibitor Iressa $(1 \mu \mathrm{M})$ partially abrogated the mitogenic effects of nicotine, whereas $1 \mu \mathrm{M}$ nifedipine had no effect. (B) Treatment with $1 \mu \mathrm{M}$ PD180 ablated Rb-Raf-1 interaction in A549 cells, whereas nifedipine and Iressa had no effect. (C) Nicotine induced phosphorylation of Src in A549 cells. (D) Densitometric analysis was performed to quantitate the results obtained by Western blotting. (E) Nicotine induced the binding of $c-S r c$ to $\beta$-nAChRs. Quiescent A549 cells were stimulated with $1 \mu \mathrm{M}$ nicotine for 15 or 30 minutes, and the binding of c-Src to $\beta$-nAChRs was assessed by IP/Western blot analysis. (F) The binding between c-Src and nAChRs was inhibited by the Src inhibitor PP2. Quiescent A549 cells were stimulated by $1 \mu \mathrm{M}$ nicotine for 15 minutes in the presence or absence of $1 \mu \mathrm{M}$ PP2, and the c-Src- $\beta$-nAChR association was assessed by IP/Western blot analysis. (G) Transfection of dominant-negative (DN) Src inhibited Rb-Raf-1 binding, whereas WT or constitutively active Src (v-Src) did not. A549 cells were transfected with the indicated plasmids. Eighteen hours after transfection, cells were rendered quiescent and subsequently stimulated with $1 \mu \mathrm{M}$ nicotine or serum for 2 hours. Western blot analysis shows the levels of the indicated proteins after transfection.

lated with $1 \mu \mathrm{M}$ nicotine for different time periods; in vitro kinase assays showed that the kinase activity associated with cyclins D and $\mathrm{E}$ was greatly enhanced upon nicotine stimulation (Figure 1, $\mathrm{E}$ and F). Furthermore, nicotine stimulation led to the dissociation of E2F1 from Rb as assessed by IP/Western blot analysis (Figure 1G, top panel), correlating with the induction of cyclin $\mathrm{D} / \mathrm{cdk} 4$ and cyclin $\mathrm{E} / \mathrm{cdk} 2$ activity as well as Rb phosphorylation (Figure 1G, middle 2 panels). It thus appears that nicotine stimulation affects various components of the cell cycle machinery similar to growth factor stimulation.

ChIP assays were performed to assess the occupancy of E2F1 and $\mathrm{Rb}$ on E2F-responsive proliferative promoters ( $c d c 6$ and $c d c 25 A)$ upon nicotine stimulation. It was observed that low levels of E2F1 and high levels of $\mathrm{Rb}$ were bound to the $c d c 6$ and $c d c 25 \mathrm{~A}$ promoters in quiescent A549 cells. Stimulation with $1 \mu \mathrm{M}$ nicotine caused the dissociation of $\mathrm{Rb}$ from both the promoters, while there were increased amounts of E2F1 bound to them (Figure $1 \mathrm{H}$, top 2 panels). PCR for the c-Fos promoter was used as a negative control; there was no Rb or E2F1 associated with this promoter (Figure $1 \mathrm{H}$, bottom panel). Similarly, significant amounts of the repressive E2Fs, namely E2F4 and E2F5, were bound to cdc6 and cdc25A promoters in quiescent cells. In contrast, low levels of the proliferative E2Fs, namely E2F1-3, were found to be associated with the cdc6 promoter in quiescent A549 cells (data not shown). Among the Rb family members, robust amounts of Rb, p130, and p107 were bound to cdc6 promoter. Nicotine stimulation caused the dissociation of Rb, p107, p130, E2F4, and E2F5 with a concomitant increase in the binding of the proliferative E2Fs E2F1-3 (data not shown). Taken together, it appears that nicotine preferentially induces the association of proliferative E2Fs to mitogenic promoters, thereby stimulating S-phase entry.

Binding of Raf-1 kinase to $R b$ is necessary for nicotine-mediated induction of cell proliferation. Previous studies had demonstrated that the Raf-1 kinase physically interacts with $\mathrm{Rb}$ upon serum stimulation and facilitates cell cycle progression; the binding of Raf- 1 to Rb was necessary for the subsequent phosphorylation by cyclins/cdks (25, 26). Since the nicotine derivative NNK has been shown to induce Raf-1 kinase activity (21), we examined whether nicotine promotes 
A

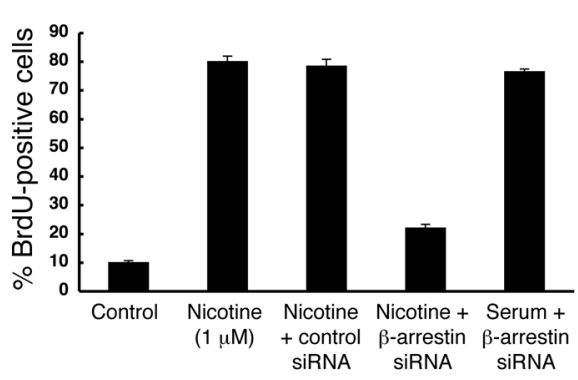

D

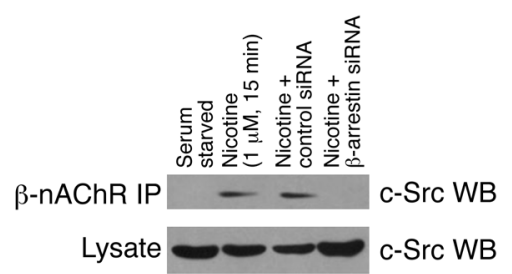

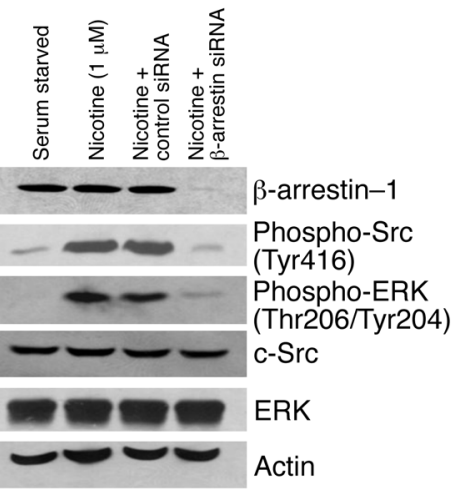
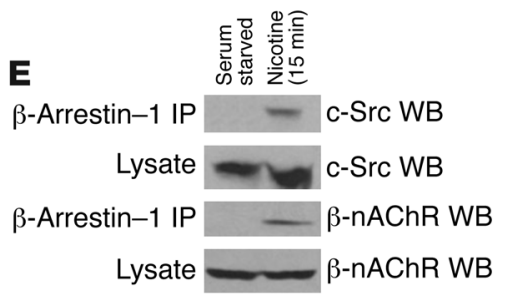

$\mathbf{F}$

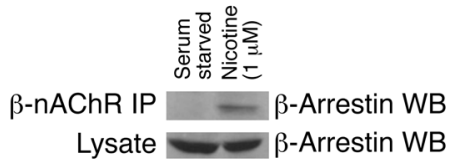

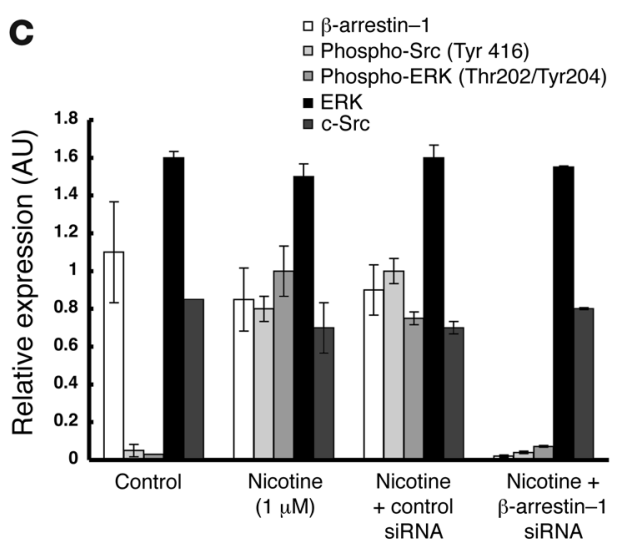

G

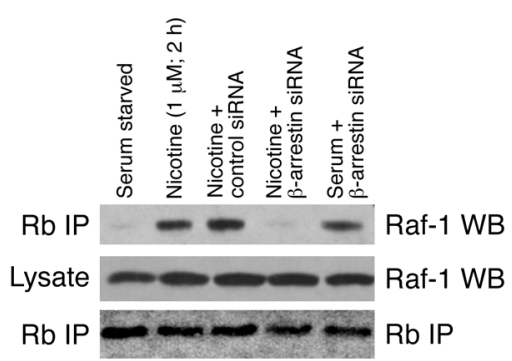

Figure 4

$\beta$-arrestin-1 mediates Src activation upon nAChR signaling. (A) Transfection of $\beta$-arrestin-1 siRNA inhibited nicotine-induced, but not seruminduced, S-phase entry in A549 cells. A nontargeting siRNA sequence was used as a control for all experiments. (B) Western blot analysis showing the suppression of $\beta$-arrestin in A549 cells upon transfection of $\beta$-arrestin-1 siRNA. Ablation of $\beta$-arrestin-1 significantly reduced nicotine-induced phosphorylated Src and phosphorylated ERK levels, whereas levels of total Src and ERK remained constant. Western blotting for actin served as the loading control. (C) Densitometric analysis was performed to quantitate the results obtained by Western blotting. (D) Nicotine induced the binding of Src to $\beta$-arrestin in A549 cells. Transfection of $\beta$-arrestin-1 siRNA abrogated the binding of $\mathrm{c}$-Src to $\beta$-arrestin, whereas a nontargeting siRNA sequence had no effect. (E) Nicotine-induced stimulation of quiescent A549 cells for 15 minutes led to the binding of $\beta$-arrestin-1 to Src and to $\beta$-nAChR. (F) The binding of $\beta$-arrestin to nAChRs seen in E was confirmed by IP using $\beta$-nAChR antibody and Western blotting for $\beta$-arrestin. (G) Transfection of $\beta$-arrestin-1 siRNA inhibited Rb-Raf-1 binding in nicotine-stimulated A549 lysates, whereas a nontargeting siRNA sequence had no effect. No effect of $\beta$-arrestin-1 siRNA was seen on serum-induced Rb-Raf- 1 binding in A549 cells.

the binding of Raf-1 to Rb. Lysates from quiescent A549 cells and primary HAECs or those stimulated with $1 \mu \mathrm{M}$ nicotine were immunoprecipitated with an anti-Rb antibody, and the presence of Raf- 1 was examined by Western blotting. As shown in Figure 2A, quiescent A549 cells and HAECs did not have any detectable Rb-Raf-1 interaction, but stimulation with nicotine induced a robust $\mathrm{Rb}-\mathrm{Raf}-1$ interaction. The $\mathrm{Rb}-\mathrm{Raf}-1$ interaction was detected up to 2 hours after nicotine stimulation and dissipated within 4 hours. The binding between $\mathrm{Rb}$ and Raf- 1 was also observed in lung cancer cell lines H23, H441, and H226 (Figure 2B) as well as in primary lung cells such as SAECs, NHBEs, and HMEC-Ls stimulated with $1 \mu \mathrm{M}$ nicotine (Figure $2 \mathrm{C}$ ). Nicotine-induced Rb-Raf-1 interaction was abolished by $\alpha$-bungarotoxin and MAA, suggesting a role for $\alpha_{7}$-nAChR in this binding (Figure 2D).

We had observed that delivery of an 8-amino acid peptide derived from Raf- 1 coupled to a carrier peptide (penetratin) could disrupt the Rb-Raf- 1 interaction and inhibit cell proliferation induced by growth factors (26). We next evaluated whether the penetratin-Raf-1 peptide conjugate affects nicotine-mediated proliferation of HAECs as well as A549 cells. Stimulation of quiescent HAECs and A549 cells with $1 \mu \mathrm{M}$ nicotine resulted in robust proliferation, as seen by
BrdU incorporation assays (Figure 2E). Nicotine stimulation in the presence of $1 \mu \mathrm{M}$ penetratin-Raf-1 peptide conjugate resulted in a significant reduction in S-phase entry, while a control scrambled peptide conjugate had no effect (Figure 2E). BrdU incorporation experiments involving penetratin-Raf-1 conjugate were performed twice, and each data point was performed in duplicate. This inhibition correlated with the disruption of the Rb-Raf- 1 interaction, as seen by IP/Western blotting (Figure 2F). It thus appears that the $\mathrm{Rb}-\mathrm{Raf}-1$ interaction facilitates S-phase entry upon nicotine stimulation as well, as in the case of growth factors. Our results indicate that the binding of Raf- 1 kinase to Rb is necessary for nicotineinducted cell proliferation and that this involves $\alpha_{7}$-nAChRs.

Enhanced association of Raf-1 kinase with $R b$ and proliferative promoters in NSCLC samples. Epidemiological studies indicate that nicotine and tobacco carcinogens are important etiologic agents contributing to the development of lung cancer $(27,28)$. Given our observation that nicotine induced the binding of Raf- 1 to $\mathrm{Rb}$, we examined whether the Rb-Raf-1 interaction was altered in human NSCLC samples. Nuclear extracts from 10 human NSCLC tumors and the adjacent normal tissue from patients were immunoprecipitated with an anti-Rb antibody, and the 


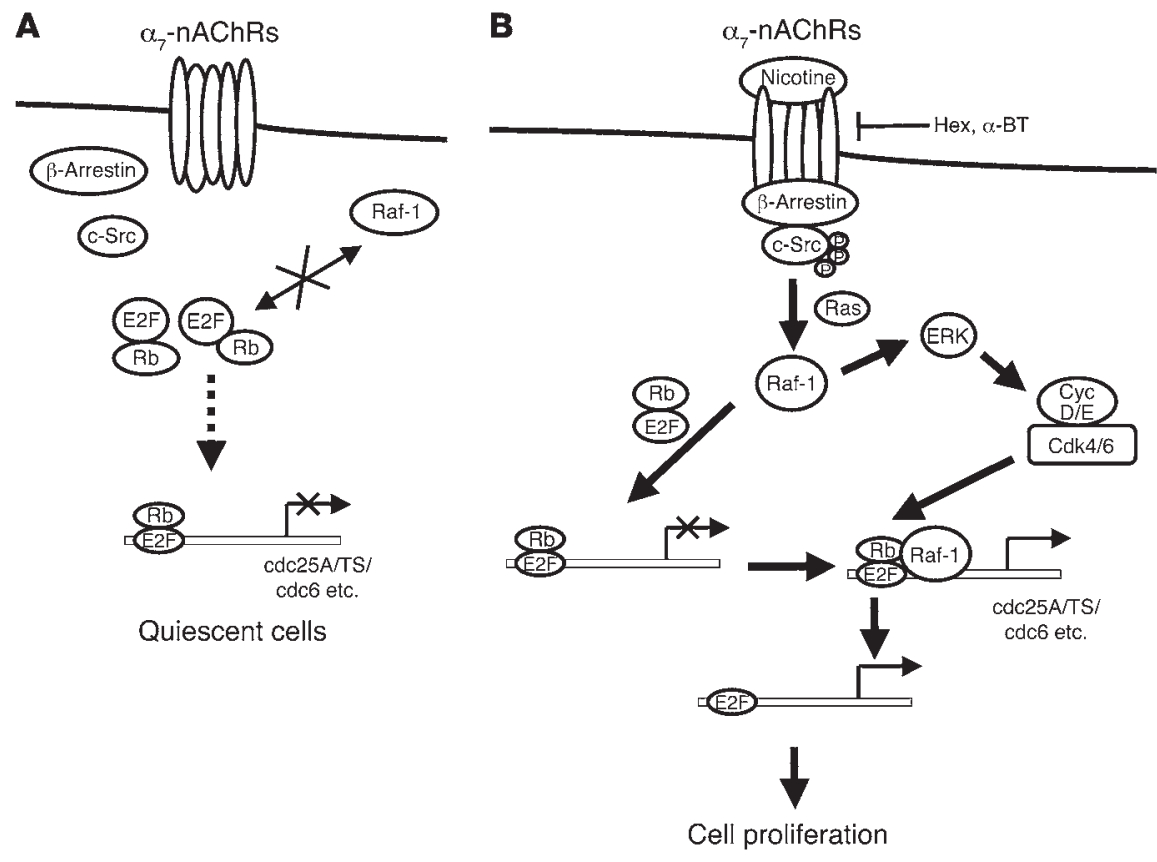

Figure 5

Schematic depicting the proliferative signaling by nAChRs in NSCLC cells. (A) Quiescent NSCLC cells do not display any association among $\beta$-arrestin, $\mathrm{Src}$, and $\mathrm{nAChRs}$. Rb is hypophosphorylated in these resting cells and is associated with E2F transcription factors. Quiescent cells do not show any binding between Raf- 1 and $\mathrm{Rb}$. E2F is present on the proliferative promoters but is repressed by $\mathrm{Rb}$. (B) Nicotine stimulation causes the assembly of oligomeric complexes involving $\beta$-arrestin, Src, and nAChRs, facilitating the activation of Src. This leads to the activation of Raf-1, which binds to Rb; activation of MAPK and cyclins/cdks also occurs. The activation of Src facilitates the binding of Raf-1 to Rb, and multimeric complexes containing Rb, Raf-1, and E2F1 occupy proliferative promoters. Sustained mitogenic signaling leads to the dissociation of Raf-1 and Rb, while E2F remains bound to the proliferative promoters facilitating S-phase entry. Ablation of $\alpha_{7}-n A C h R$ subunits and $\beta$-arrestin-1, inhibition of Src activation, and disruption of the Rb-Raf-1 interaction all blocked nicotine-induced proliferation of NSCLC cells. TS, thymidylate synthase.

presence of Raf-1 was examined by Western blotting. As shown in Figure 2G, there were elevated levels of Rb-Raf-1 interaction in 8 of 10 tumors compared with the adjacent normal tissue. This suggests that increased Rb-Raf- 1 interaction correlates with oncogenesis. Since Raf- 1 reverses $\mathrm{Rb}$-mediated repression of E2F1 transcription, we examined the occupancy of E2F1, Rb, and Raf- 1 on 2 E2F-regulated proliferative promoters in human NSCLC tumor samples. Toward this purpose, ChIP assays were performed on 2 NSCLC tumor samples along with their adjacent matched normal lung tissues. As seen in Figure $2 \mathrm{H}$, both $\mathrm{E} 2 \mathrm{~F} 1$ and $\mathrm{Rb}$ were bound to the $\mathrm{cdc} 25 \mathrm{~A}$ and $\mathrm{cdc} 6$ promoters in normal tissues. However, only low levels of Raf-1 were associated with the promoters. In contrast, a significant amount of Raf-1 was bound to both the cdc 6 and cdc25A promoters in NSCLC tumor samples. These results suggest that association of Raf-1 with $\mathrm{Rb}$ correlates with enhanced expression of proliferative promoters and oncogenesis.

Activation of Src is vital for nicotine-mediated Rb-Raf binding. It has been shown that nicotine can induce calcium channels and activate Src in neuronal as well as certain non-neuronal cells $(29,30)$; it has also been suggested that EGFR contributes to AAChR signaling (17). The contribution of these molecules to nicotine-induced proliferation of NSCLC cells was examined by BrdU incorporation (Figure 3A). Quiescent A549 cells showed $12.5 \% \pm 1.0 \%$ cells in S-phase; upon nicotine stimulation, $86 \% \pm 2.3 \%$ cells were found to enter S-phase. The presence of $1 \mu \mathrm{M}$ of EGFR inhibitor Iressa (gefitinib) abrogated the mitogenic activity of nicotine (reduction of S-phase cells from $86 \% \pm 2.3 \%$ to $44 \% \pm 1.3 \%$ ), whereas $1 \mu \mathrm{M}$ of the calcium channel blocker nifedipine did not. In contrast, $1 \mu \mathrm{M}$ of the Src inhibitor PD180 abrogated nicotineinduced proliferation of A549 cells (reduction of cell proliferation from $86 \% \pm 2.3 \%$ to $22 \% \pm 0.7 \%)$. The graphs shown in Figure $3 \mathrm{~A}$ represent the average of 2 independent experiments, each data point being performed in duplicate. Next we examined whether these molecules mediate the $\mathrm{Rb}-\mathrm{Raf}-1$ interaction upon nicotine stimulation. A549 cells were rendered quiescent by serum starvation and subsequently stimulated with $1 \mu \mathrm{M}$ nicotine. IP/Western blot analysis of the lysates showed that treatment of cells with $1 \mu \mathrm{M}$ of EGFR inhibitor Iressa or $1 \mu \mathrm{M}$ of the calcium channel blocker nifedipine did not affect Rb-Raf-1 binding (Figure 3B). However, the Src inhibitor PD180 ablated the association of Rb and Raf- 1 , showing that the activation of Src is a vital signaling event facilitating the Rb-Raf-1 interaction (Figure 3B). We observed that nicotine induces phosphorylation of EGFR starting at 4 hours (data not shown), whereas the Rb-Raf-1 interaction precedes this activation; this suggests that induction of EGFR is a secondary event that follows the binding of Raf- 1 to Rb.

We also studied the role of Src in nicotine-induced cell proliferation. Stimulation with $1 \mu \mathrm{M}$ nicotine upregulated the levels of phosphorylated Src in A549 cells, while overall levels of Src remained constant (Figure 3, C and D). Figure 3D represents the densitometric analysis of Western blots performed with independent sets of lysates. We next examined whether nicotine stimulation induces the binding of Src to nAChRs. Quiescent A549 cells were stimulated with $1 \mu \mathrm{M}$ nicotine, and the binding of $\mathrm{nAChR}$ with Src was examined by IP/Western blot analysis (Figure 3E). Previous studies have implicated the binding of $\beta$-nAChR with Src in the regulation of neuromuscular junctions as well as acrosome reactions in non-neuronal cells, hence we conjectured that the $\beta$-nAChR was probably the subunit that physically interacted with Src in NSCLC cells $(31,32)$. Therefore, a pan- $\beta$-nAChR subunit antibody was used to IP quiescent and nicotine-stimulated A549 lysates, and the presence of Src was examined by Western blotting. Src was found to bind nAChRs within 15 minutes of nicotine stimulation. Interestingly, the nAChR-Src interaction was completely ablated by $1 \mu \mathrm{M}$ of the Src inhibitor PP2, suggesting that the activation of Src is essential for its binding to nAChRs (Figure 3F). We repeated the IP/Western blot experiments with a pan monoclonal antibody to $\alpha$-nAChR; Src was detected in the IPs of nicotine-stimulated lysates (data not shown). The $\alpha$ and $\beta$ subunits of $\mathrm{nAChR}$ associate to form a pentamer, explaining the presence of Src in both the IPs. 
The role of activated Src in inducing the Rb-Raf-1 proliferative pathway was further examined. A549 cells were transiently transfected with FLAG-Raf-1 and Myc-Rb in the presence of wt Src, dominant negative Src or constitutively activated Src (v-Src). Eighteen hours post transfection, cells were rendered quiescent and stimulated with $1 \mu \mathrm{M}$ nicotine for 2 hours; binding of Raf- 1 to $\mathrm{Rb}$ was assessed by IP/Western blot analysis. Figure $3 \mathrm{G}$ shows that the Rb-Raf- 1 interaction is observed in cells transfected with WT and constitutively activated Src; however, dominant-negative Src inhibited the nicotine-induced Rb-Raf-1 binding. These results suggest that the activation of Src is a crucial signaling event mediating the nicotine-induced Rb-Raf- 1 proliferative pathway.

$\beta$-arrestin-1 facilitates the recruitment of Src to $n A C b R s$. We next sought to elucidate the molecular mechanisms by which Src is activated upon nicotine stimulation. Data from Luttrell et al. have shown that the scaffolding protein $\beta$-arrestin- 1 binds to Src and recruits it to the $\beta$-adrenergic receptors $(33,34)$. Given that certain ligands can activate both $\beta$-adrenergic and nicotinic receptors, we examined whether $\beta$-arrestin- 1 mediates the recruitment of Src to nAChRs. The effect of $\beta$-arrestin-1 on nicotine-induced proliferation was first assessed by siRNA techniques (35). It was found that transfection of $\beta$-arrestin- 1 siRNA ablated nicotineinduced S-phase entry but had no effect on serum-induced proliferation of A549 cells (Figure 4A). The treatment of A549 with nicotine caused a significant upregulation (from $10 \% \pm 0.6 \%$ to $80 \% \pm 0.2 \%$ ) of S-phase cells. The presence of $\beta$-arrestin- 1 siRNA in nicotine-stimulated A549 cells abrogated cell proliferation (decrease in BrdU-positive cells from $80 \% \pm 0.2 \%$ to $22 \% \pm 1.3 \%$ ). Additionally, $\beta$-arrestin- 1 siRNA caused downregulation of activated Src and phosphorylated ERK in nicotine-stimulated A549 cells; levels of total ERK and total Src remained constant (Figure 4, $\mathrm{B}$ and $\mathrm{C}$ ). The siRNA transfections were performed in duplicate and repeated twice each for both BrdU assays as well as immunoblotting experiments. The Western blotting experiments shown in Figure 4B were performed with independent sets of lysates, and Figure $4 \mathrm{C}$ represents the average of 2 experiments. The requirement for $\beta$-arrestin- 1 in recruiting Src to $n A C h R$ was next examined. IP/Western blot analysis showed that Src was not associated with nAChRs in quiescent cells but physically interacted with $\beta$-nAChR within 15 minutes of nicotine stimulation (Figure 4D); transfection of $\beta$-arrestin-1 siRNA abrogated the $\beta$-nAChR-Src interaction, while a control siRNA had no effect. These results suggest that $\beta$-arrestin is necessary for mediating the binding of Src to $\mathrm{nAChR}$ upon nicotine stimulation.

Since $\beta$-arrestin- 1 is a scaffolding protein (34), we examined whether $\beta$-arrestin-1 physically interacts with Src as well as nAChRs. Quiescent and nicotine-stimulated A549 lysates were immunoprecipitated with a $\beta$-arrestin polyclonal antibody and immunoblotted for endogenous Src and $\beta$-nAChR. Figure 4E shows that Src and nAChR were detected in $\beta$-arrestin-1 IPs in nicotine-stimulated, but not quiescent, cells. These results were confirmed by performing the IP with a pan- $\beta$-nAChR monoclonal antibody and immunoblotting for $\beta$-arrestin. It was found that a significant amount of $\beta$-arrestin bound to $\mathrm{nAChR}$ within 15 minutes of nicotine stimulation (Figure $4 \mathrm{~F}$ ). The role of $\beta$-arrestin- 1 in mediating the Rb-Raf- 1 interaction in nicotinestimulated A549 cells was next assessed. The transfection of $\beta$-arrestin-1 siRNA completely abrogated Rb-Raf- 1 binding in nicotine-stimulated A549 cells, but not in serum-stimulated cells (Figure 4G). Taken together, these data suggest that $\beta$-arrestin-1 plays a major role in mediating the proliferative effects of nicotine by recruiting Src to the membrane-bound nAChRs, leading to its activation and cell proliferation.

\section{Discussion}

While the genotoxic effects of tobacco carcinogens have long been recognized $(1,36)$, the contribution of tobacco components to oncogenesis by cell surface receptor signaling is relatively unexplored. Studies from Cooke's laboratory showed that nicotine and NNK can promote cell proliferation and angiogenesis in a receptor-dependent manner, but the molecules mediating these events have not yet been fully identified $(4,5)$. Here we showed that nicotine functions like a growth factor and that nAChRs have significant proliferative effects despite lacking intrinsic tyrosine kinase activity. Thus nicotine could activate components of the cell cycle machinery, cause upregulation of cyclin $\mathrm{E} / \mathrm{cdk} 2$ and cyclin D/cdk4 kinase activity, mediate dissociation of E2F1 from $\mathrm{Rb}$, and induce $\mathrm{Rb}$ phosphorylation in NSCLC cells. Furthermore, ChIP assays demonstrated that nicotine caused the binding of E2F1 and Raf- 1 to proliferative promoters. Thus the signaling pathways induced by nicotine in NSCLC cells resemble those involved in growth factor stimulation.

A schematic of mitogenic signaling in NSCLCs is shown Figure 5. In quiescent cells, there is no association of $\beta$-arrestin and Src to $\mathrm{nAChRs}$; also, E2F1 bound to proliferative promoters is repressed by $\mathrm{Rb}$ bound to the promoter (Figure $5 \mathrm{~A}$ ). However, the binding of nicotine to nAChRs causes the recruitment of $\beta$-arrestin and Src to the nicotinic receptors, resulting in the activation of the MAPK and Rb-Raf-1 pathways (Figure $5 \mathrm{~B}$ ). These events cause the recruitment of E2F1, Rb, and Raf-1 on E2F-responsive proliferative promoters. The inactivation of $\mathrm{Rb}$ by Raf- 1 facilitates the dissociation of $\mathrm{Rb}$ from the promoters, which - combined with the increased binding of E2F1 - causes transcription of S-phase genes and cell cycle progression.

Our earlier studies have shown that the binding of the signaling kinase Raf- 1 to the $\mathrm{Rb}$ protein was a necessary step for cell cycle progression induced by serum and growth factors $(25,26)$. Binding of Raf- 1 to $\mathrm{Rb}$ was necessary for its subsequent inactivation by cyclin/cdks; inhibition of the binding of Raf-1 prevented Rb phosphorylation, cell cycle progression, angiogenic tubule formation, and tumor growth in nude mice (26). Exposure of cells to nicotine induces the same interaction, facilitating cell proliferation. Our finding that the levels of Rb-Raf-1 complexes in human NSCLC tumors were greater than those in adjacent normal tissues suggests that the Rb-Raf-1 pathway probably contributes to oncogenesis; the presence of increased levels of Raf-1 on proliferative promoters in human NSCLC tumors supports this hypothesis. Thus it is likely that tumors exposed to nicotine have an added proliferative advantage; indeed, smokers have been found to respond less effectively to chemotherapy and were found to have increased metastasis of breast cancers (37-39). Our recent studies have shown that nicotine by itself could protect NSCLC cells from apoptosis induced by chemotherapeutic drugs by upregulating X-linked inhibitor of apoptosis and survivin (40). Cigarette smoke extract has been shown to promote the growth of gastric, colon, and bladder cancer and to upregulate the invasion of human gastric cancer $(13,16,17,41)$; our unpublished results show that nicotine by itself can promote the proliferation of cell lines derived from pancreatic, breast, and glial tumors as well. It can be imagined that signaling through the nAChRs contributes to these processes. 
It appears that $\beta$-arrestin-1 and Src kinase are key players in mediating the mitogenic effects of nicotine. The Src family of protein tyrosine kinases has been found to be a critical component of multiple receptor-mediated signaling pathways that regulate proliferation, survival, metastasis, and angiogenesis. Src has been shown to functionally interact with several receptors, like the $G$ protein-coupled receptors (GPCRs), which lack intrinsic tyrosine kinase activity and connect them to growth regulatory pathways like the MAPK cascade $(33,42)$. We found that the activation of Src is an important upstream signaling event that mediates Rb-Raf-1 binding upon nicotine stimulation. Studies in neuronal systems as well as nAChR-transfected cells have shown that the interaction of Src and its family members regulate the function of neuromuscular junctions and amplitude of whole-cell inward currents $(17,19$, $29,32)$. Recent evidence also shows that nicotine and NNK cause Src activation in lung cancer cells $(19,29)$. These observations lend support for a role for Src in smoking-related cancers.

Interestingly, $\beta$-arrestin seems to be vital for nicotine-mediated activation of Src and cell proliferation. The proteins in the $\beta$-arrestin family have been shown to serve as scaffold proteins that recruit a broad spectrum of signaling molecules to membranebound receptors in a highly cocoordinated manner. $\beta$-Arrestins are known to regulate endocytotic pathways, connect GPCRs to MAPK pathways, regulate chemotactic migration and motility, and contribute to antiapoptotic signaling $(33,34,43)$. Recent studies have implicated the $\beta$-arrestin family of proteins in Notch signaling, TLR-interleukin-1 signaling, and regulation of gene expression by facilitating histone acetylation (44-47). Data from Ahn et al. and Fong et al. show that $\beta$-arrestin-knockout mice and $\beta$-arrestin- 1 siRNA-transfected cells demonstrate impaired ERK activation and defective chemotactic responses $(35,48)$. $\beta$-Arrestin-GPCR complexes were also found to be key players in determining the mechanism and functional consequence of ERK activation (49). In addition, recent studies have shown that $\beta$-arrestin- 1 plays a major role in the metastasis of colorectal cancer (41). Our data showed that $\beta$-arrestin is required for $n A C h R$-mediated activation of the MEK/ERK pathway and proliferation of NSCLCs. It appears that $\beta$-arrestin acts as a critical link between the mitogenic signals from the nAChRs and the cell cycle machinery, which raises the possibility that nicotine might be promoting tumor progression and metastasis by activating $\beta$-arrestin- 1 . Indeed, it has been reported that there is an association between smoking and increased risk of lung metastasis in breast cancer patients $(38,39)$.

While tobacco carcinogens can initiate and promote tumorigenesis, the results of the present study raise the possibility that exposure to nicotine, by either cigarette substitutes or nicotine supplements, might confer a proliferative advantage to tumors already initiated. This contention is supported by the findings that nicotine can prevent apoptosis induced by various agents, thus conferring a survival advantage as well $(10,50-52)$. Elucidation of the signaling events mediated by nAChRs present on nonneuronal cells may open new avenues for targeting cancer therapy, focusing on agents that inhibit the $\beta$-arrestin-Src signaling axis or Rb-Raf-1 interaction.

\section{Methods}

Cell culture and transfection. HAECs and HMEC-Ls (Cambrex) were maintained in endothelial growth medium (EGM) with 5\% FBS. (Cambrex). NHBEs (Cambrex) were maintained in BEGM containing growth supplement per the supplier's instructions. SAECs were cultured in SAGM sup- plemented with growth factors and 1\% fat-free BSA. A549 (bronchoalveolar carcinoma) cells were maintained in DMEM supplemented with $10 \%$ FBS. $\mathrm{H} 441, \mathrm{H} 226$, and $\mathrm{H} 23$ cells were cultured in RPMI-1640 supplemented with $10 \%$ FBS. H441, H226, H23, and A549 cells were serum starved by incubating them in serum-free medium for 48 hours. HAECs and HMEC-Ls were rendered quiescent by culturing in EGM containing $0.5 \% \mathrm{FBS}$ for 24 hours. NHBEs and SAECs were rendered quiescent by incubating them with BEGM and SAGM containing one-fourth the growth supplements and one-fourth the amount of fat-free BSA. Thereafter, the cells were stimulated with $1 \mu \mathrm{M}$ nicotine (Sigma-Aldrich) for the indicated time points (Figure 2). All transient transfections were performed with Lipofectamine 2000 Transfection Reagent (Invitrogen) using $8 \mu$ g of each plasmid according to the manufacturer's instructions.

Lysate preparation and IP/Western blots. Lysates from cells treated with different agents were prepared by NP-40 lysis (25). Cells were treated as indicated in Figures 1-4 and subsequently washed twice with ice-cold PBS and scraped. The cells were spun at $800 \mathrm{~g}$ and lysed using M2 lysis buffer (20 mM Tris-HCl, pH 7.6, 0.5\% NP-40, 250 mM NaCl, 3 mM EGTA, and $3 \mathrm{mM}$ EDTA) containing protease inhibitors. The lysate was rotated at $4{ }^{\circ} \mathrm{C}$ for 30 minutes and subsequently spun at $18,000 \mathrm{~g}$ for 15 minutes. The supernatant was removed, and the protein content was quantified by Bradford assay. Equal amounts of proteins $(100 \mu \mathrm{g})$ were separated on SDS-PAGE and transferred to nitrocellulose membranes (Bio-Rad) blocked by $5 \%$ nonfat dry milk in PBS/0.1\% Tween-20 and incubated with the appropriate primary antibodies. HRP-conjugated secondary antibodies (Pierce Biotechnology) were used and signals detected by ECL (GE Healthcare). Physical interaction between proteins in vivo was analyzed by IP/Western blot analysis using $200 \mu \mathrm{g}$ of lysates and $1 \mu \mathrm{g}$ of each antibody, as described previously $(25,26)$. For IPs involving $\beta$-nAChR antibody, $700 \mu \mathrm{g}$ of lysate and $3 \mu \mathrm{g}$ of antibody was used for the IP reaction. The concentration of hexamethonium bromide (Sigma-Aldrich) was $20 \mu \mathrm{M}$, whereas $1 \mu \mathrm{M}$ atropine (Sigma-Aldrich) was used as the control. The inhibitors of nAChR subunits, namely $\alpha$-lobeline (Tocris), $\alpha$-bungarotoxin (Sigma-Aldrich), DH $\beta E$ (Sigma-Aldrich), and MAA (Tocris), were used at a concentration of $1 \mu \mathrm{M}$ $(4,5)$. Iressa and PD180 were obtained as kind gifts from E. Haura (University of South Florida) and R. Jove (City of Hope Cancer Center, Duarte, California, USA) and were used at a concentration of $1 \mu \mathrm{M}$. The Src inhibitor PP2 (Alexis Biochemicals, Axxora) and nifedipine (Sigma-Aldrich) were used at a concentration of $1 \mu \mathrm{M}$.

Monoclonal antibodies against $\beta$-nAChR and $\alpha$-nAChR were obtained from Chemicon International. Polyclonal $\beta$-arrestin- 1 antibody and monoclonal $\mathrm{Rb}$ antibodies were purchased from Calbiochem, EMD Biosciences. Monoclonal c-Src antibody was obtained from Upstate USA Inc. Polyclonal Src, p107, and nAChR subunit antibodies; monoclonal E2F1 antibody; polyclonal E2F2, E2F3, E2F4, and E2F5 antibodies; monoclonal cyclin D and Myc antibodies; and polyclonal cyclin E antibodies were obtained from Santa Cruz Biotechnology Inc. Monoclonal Raf-1 and 130 antibodies were obtained from BD Biosciences - Pharmingen. Phosphorylated Src, phosphorylated EGFR, phosphorylated ERK, total ERK, and total EGFR polyclonal antibodies were obtained from Cell Signaling Technology. Monoclonal FLAG and actin antibodies were obtained from Sigma-Aldrich.

In vitro kinase assays. Lysates from A549 cells stimulated with nicotine for different durations were used for the kinase assays. The lysates used for the cyclin $\mathrm{D} / \mathrm{cdk} 4$ kinase assay were prepared as described previously (53). IPs using cyclin D monoclonal antibody or cyclin E polyclonal antibody (Santa Cruz Biotechnology Inc.) were carried out as described previously $(26,54)$. After washing the beads in IP buffer, the immune complexes were washed twice in kinase buffer (50 mM HEPES, pH 7.9, $10 \mathrm{mM} \mathrm{MgCl}_{2}$, $5 \mathrm{mM} \mathrm{MnCl}_{2}, 1 \mathrm{mM} \mathrm{DTT}$, and $10 \mathrm{mM} \beta$-glycerolphosphate). The kinase 
reaction was carried out in a total volume of $10 \mu \mathrm{l}$ containing $1 \mu \mathrm{g}$ histone H1 (Upstate USA Inc.) as substrate, $100 \mu \mathrm{M}$ ATP, and $10 \mu \mathrm{Ci} \gamma^{32} \mathrm{P}-\mathrm{ATP}$ in kinase assay buffer at $37^{\circ} \mathrm{C}$ for 30 minutes (25). For the cyclin D/cdk4 kinase assay, $1 \mu \mathrm{g}$ of purified bacterially expressed human Rb (QED Bioscience Inc.) was used as the substrate, and the kinase reaction was performed at $30^{\circ} \mathrm{C}$ for 30 minutes (26). Samples were subsequently boiled in SDS sample loading buffer and resolved by polyacrylamide gel electrophoresis. The phosphorylation of histone $\mathrm{H} 1$ or $\mathrm{Rb}$ was visualized by autoradiography. Subsequently, the gel was rehydrated and stained with Coomassie Blue to check the levels of substrate in each reaction.

Coupling of peptide and penetratin. A peptide corresponding to residues 10-18 of Raf- 1 was synthesized with a cysteine residue at the $C$ terminus (ISNGFGFKC). The Raf-1 peptide $(150 \mu \mathrm{M})$ was incubated with an equal amount of penetratin (QBiogene) per the manufacturer's protocols (55). Coupling was checked by electrophoresis on an $18 \%$ polyacrylamide gel. For competing the binding of Raf- 1 to $\mathrm{Rb}$ in vivo, $1 \mu \mathrm{M}$ of this conjugate was included in the growth medium. Activated penetratin was also coupled to a scrambled peptide sequence containing the same amino acid content as the Raf- 1 peptide. The penetratin-Raf- 1 scrambled peptide was used as a control for all experiments involving penetratin-Raf-1 conjugate peptide.

Proliferation assays. BrdU labeling kits were obtained from Roche Diagnostics. HAECs were rendered quiescent by culturing in EGM containing $0.5 \%$ FBS for 24 hours and restimulated with $1 \mu \mathrm{M}$ nicotine for 18 hours. A549 cells were serum starved by incubating them in serum-free medium for 48 hours. Where necessary, $1 \mu \mathrm{M}$ of the penetratin-Raf- 1 peptide conjugate or the scrambled peptide conjugate (used as control) was included during stimulation, as indicated in Results and Discussion. For some experiments nicotine stimulation was performed in the presence of $20 \mu \mathrm{M}$ hexamethonium bromide or $1 \mu \mathrm{M}$ atropine. BrdU-positive cells were visualized by phase-contrast microscopy. Briefly, 100 cells were counted per field, and 3 independent fields were counted per replicate. The entire experiment was performed twice, with each data point being performed in duplicate.

siRNA transfection and assays. Chemically synthesized double-stranded siRNA for $\alpha_{7}$-nAChR and $\beta$-arrestin- 1 were purchased from Ambion and QIAGEN, respectively. The siRNAs were transfected at a concentration of 50 pmol each ( $\beta$-arrestin-1 siRNA was transfected at a concentration of $40 \mathrm{pmol}$ ) or in combination in A549 cells using Oligofectamine reagent (Invitrogen) per the manufacturer's instructions. A nontargeting siRNA sequence (Santa Cruz Biotechnology Inc.) was used as a control for all transfection experiments. Eighteen hours after transfection, the cells were rendered quiescent for 24 hours using serum-free DMEM; subsequently, the cells were treated with $1 \mu \mathrm{M}$ nicotine. S-phase entry in the cells was ascertained using BrdU assay (Roche Diagnostics). All siRNA transfection experiments were performed twice; each sample was performed in duplicate and subsequently harvested for BrdU assays or Western blotting analysis. The Western blots were performed twice to confirm the specific silencing of each gene.

ChIP assays. Quiescent A549 cells were stimulated with $1 \mu \mathrm{M}$ nicotine for 12 hours. For each IP reaction, $2.5 \times 10^{7}$ cells were used. Cells were cross-linked with $1 \%$ formaldehyde for 10 minutes at room temperature (56). The cross-linking was terminated by addition of glycine to a final concentration of $0.125 \mathrm{M}$. Cells were harvested and sonicated, and lysates were immunoprecipitated with the indicated antibodies. The differential binding of E2F1-5, Rb, p130, p107, and Raf-1 to the cdc6 and cdc25A were analyzed by PCR. PCR for c-Fos was used as the control in all experiments. The sequences of the PCR primers used have been described earlier (56).

Human NSCLC tumor tissues and adjacent normal lung tissue were obtained from the Tumor Tissue Repository at Moffitt Cancer Center. The tissues were chopped with a razor blade or scalpel into small pieces and resuspended in serum-free media. For each antibody, $0.03 \mathrm{~g}$ tissue was used. The tissues were crosslinked with $1 \%$ formaldehyde and rotated for $10 \mathrm{~min}$ utes at room temperature $(57,58)$. The cross-linking reaction was terminated by adding glycine to a final concentration of $0.125 \mathrm{M}$. The tissue samples were centrifuged at $250 \mathrm{~g}$ for 5 minutes, and the supernatant was discarded. The sample was homogenized on ice using a Polytron Homogenizer and centrifuged at $250 \mathrm{~g}$ to collect the cells. Thereafter ChIP lysates were made and the assay was performed as per standard protocols (56).

\section{Acknowledgments}

We thank R. Jove, E. Haura, K.L. Guan, G. Bepler, A. Sharma, and R. Lefkowitz for generous gifts of constructs and reagents. This work is supported by NIH grant CA63136 from the National Cancer Institute to S. Chellappan.

Received for publication February 8, 2006, and accepted in revised form June 1, 2006.

Address correspondence to: Srikumar Chellappan, Department of Interdisciplinary Oncology, H. Lee Moffitt Cancer Center and Research Institute, University of South Florida, 12902 Magnolia Drive, Tampa, Florida 33612, USA. Phone: (813) 745-6892; Fax: (813) 745-6748; E-mail: ChellaSP@moffitt.usf.edu.
1. Hecht, S.S. 1999. DNA adduct formation from tobacco-specific N-nitrosamines. Mutat. Res. 424:127-142.

2. Schuller, H.M., and Orloff, M. 1998. Tobacco-specific carcinogenic nitrosamines. Ligands for nicotinic acetylcholine receptors in human lung cancer cells. Biochem. Pharmacol. 55:1377-1384.

3. Gotti, C., and Clementi, F. 2004. Neuronal nicotinic receptors: from structure to pathology. Prog. Neurobiol. 74:363-396.

4. Heeschen, C., et al. 2001. Nicotine stimulates angiogenesis and promotes tumor growth and atherosclerosis. Nat. Med. 7:833-839.

5. Heeschen, C., Weis, M., Aicher, A., Dimmler, S., and Cooke, J.P. 2002. A novel angiogenic pathway mediated by non-neuronal nicotinic acetylcholine receptors. J. Clin. Invest. 110:527-536. doi:10.1172/ JCI200214676.

6. Sharma, G., and Vijayaraghavan, S. 2002. Nicotinic receptor signaling in nonexcitable cells. J. Neurobiol. 53:524-534.

7. Wessler, I., Kirkpatrick, C.J., and Racke, K. 1998. Nonneuronal acetylcholine, a locally acting molecule, widely distributed in biological systems: expression and function in humans. Pharmacol. Ther. 77:59-79.

8. Minna, J.D., Fong, K., Zochbauer-Muller, S., and Gazdar, A.F. 2002. Molecular pathogenesis of lung cancer and potential translational applications. Cancer J. 8(Suppl. 1):S41-S46.

9. Villablanca, A.C. 1998. Nicotine stimulates DNA synthesis and proliferation in vascular endothelial cells in vitro. J. Appl. Physiol. 84:2089-2098.

10. Manackjee, R., and Minna,J.D. 1990. Opioid and nicotine receptors affect growth regulation of human lung cancer cell lines. Proc. Natl. Acad. Sci. U. S. A 87:3294-3298.

11. Cattaneo, M.G., D’Atri, F., and Vicentini, L.M. 1997. Mechanisms of mitogen-activated protein kinase activation by nicotine in small-cell lung carcinoma cells. Biochem. J. 328:499-503.

12. Minna, J.D. 2003. Nicotine exposure and bronchial epithelial cell nicotinic acetylcholine receptor expression in the pathogenesis of lung cancer. J. Clin. Invest. 111:31-33. doi:10.1172/JCI200317492.

13. Trombino, S., et al. 2004. Role of the non-neuronal human cholinergic system in lung cancer and meso- thelioma: possibility of new therapeutic strategies. Curr. Med. Chem. Anticancer Agents. 4:535-542.

14. Melkonian, G., Cheung, L., Marr, R., Tong, C., and Talbot, P. 2002. Mainstream and sidestream cigarette smoke inhibit growth and angiogenesis in the day 5 chick chorioallantoic membrane. Toxicol. Sci. 68:237-248.

15. Song, P., et al. 2003. Acetylcholine is synthesized by and acts as an autocrine growth factor for small cell lung carcinoma. Cancer Res. 63:214-221.

16. Shin, V.Y., and Cho, C.H. 2005. Nicotine and gastric cancer. Alcohol. 35:259-264.

17. Ye, Y.N., et al. 2004. Nicotine promoted colon cancer growth via epidermal growth factor receptor, c-Src, and 5-lipoxygenase-mediated signal pathway. J. Pharmacol. Exp. Ther. 308:66-72.

18. Conklin, B.S., Zhao, W., Zhong, D., and Chen, C. 2002. Nicotine and cotinine upregulate vascular endothelial growth factor expression in endothelial cells. Am. J. Pathol. 160:413-419.

19. Xu, L., and Deng, X. 2005. Protein kinase Ciota promotes nicotine-induced migration and invasion of cancer cells via phosphorylation of micro- and 
m-calpains. J. Biol. Chem. 281:4457-4466.

20. Shin, V.Y., et al. 2005. Nicotine induces cyclooxygenase- 2 and vascular endothelial growth factor receptor-2 in association with tumor-associated invasion and angiogenesis in gastric cancer. Mol. Cancer Res. 3:607-615.

21. Jull, B.A., Plummer, H.K., 3rd, and Schuller, H.M. 2001. Nicotinic receptor-mediated activation by tobacco-specific nitrosamine NNK of a Raf-1/ MAPkinase pathway, resulting in phosphorylation of c-myc in human small cell lung carcinoma and pulmonary neuroendocrine cells. J. Cancer Res. Clin. Oncol. 127:707-717.

22. Chu, M., Guo, J., and Chen, C.Y. 2005. Long-term exposure to nicotine, via ras pathway, induces cyclin D1 to stimulate G1 cell cycle transition. J. Biol. Chem. 280:6369-6379.

23. Nevins, J.R. 2001. The Rb/E2F pathway and cancer. Hum. Mol. Genet. 10:699-703.

24. Stevaux, O., and Dyson, N.J. 2002. A revised picture of E2f Transcriptional regulation and $\mathrm{Rb}$ function. Curr. Opin. Cell Biol. 14:684-691.

25. Wang, S., Ghosh, R.N., and Chellappan, S.P. 1998. Raf- 1 physically interacts with $\mathrm{Rb}$ and regulates its function: a link between mitogenic signaling and cell cycle regulation. Mol. Cell. Biol. 18:7487-7498.

26. Dasgupta, P., et al. 2004. Disruption of the Rb-Raf-1 interaction inhibits tumor growth and angiogenesis. Mol. Cell. Biol. 24:9527-9541.

27. Johnson, B.E. 1998. Tobacco and lung cancer. Prim. Care. 25:279-291.

28. Sekhon, H.S., Wright, J.L., and Churg, A. 1994. Cigarette smoke causes rapid cell proliferation in small airways and associated pulmonary arteries. Am. J. Physiol. 267:L557-L563.

29. Charpantier, E., et al. 2005. Alpha7 neuronal nicotinic acetylcholine receptors are negatively regulated by tyrosine phosphorylation and Src-family kinases. J. Neurosci. 25:9836-9849.

30. Sher, E., et al. 1998. Nicotinic receptors and calcium channels in small cell lung carcinoma. Functional role, modulation, and autoimmunity. Ann. N. Y. Acad. Sci. 841:606-624.

31. Colledge, M., and Froehner, S.C. 1998. Interaction between the nicotinic acetylcholine receptor and Grb2. Implications for signaling at the neuromuscular junction. Ann. N. Y. Acad. Sci. 841:17-27.

32. Kumar, P., and Meizel, S. 2005. Nicotinic acetylcho- line receptor subunits and associated proteins in human sperm. J. Biol. Chem. 280:25928-25935.

33. Luttrell, L.M., et al. 1999. Beta-arrestin-dependent formation of beta2 adrenergic receptor-Src protein kinase complexes. Science. 283:655-661.

34. Lefkowitz, R.J., and Shenoy, S.K. 2005. Transduction of receptor signals by beta-arrestins. Science. 308:512-517.

35. Ahn, S., Nelson, C.D., Garrison, T.R., Miller, W.E., and Lefkowitz, R.J. 2003. Desensitization, internalization, and signaling functions of beta-arrestins demonstrated by RNA interference. Proc. Natl. Acad. Sci. U. S. A. 100:1740-1744.

36. Hecht, S.S., et al. 2002. Inhibition of lung tumorigenesis in $\mathrm{A} / \mathrm{J}$ mice by $\mathrm{N}$-acetyl-S-(N-2-phenethylthiocarbamoyl)-L-cysteine and myo-inositol, individually and in combination. Carcinogenesis. 23:1455-1461.

37. Richardson, G.E., et al. 1993. Smoking cessation after successful treatment of small-cell lung cancer is associated with fewer smoking-related second primary cancers. Ann. Intern. Med. 119:383-390.

38. Murin, S., and Inciardi, J. 2001. Cigarette smoking and the risk of pulmonary metastasis from breast cancer. Chest. 119:1635-1640.

39. Murin, S., Pinkerton, K.E., Hubbard, N.E., and Erickson, K. 2004. The effect of cigarette smoke exposure on pulmonary metastatic disease in a murine model of metastatic breast cancer. Chest. 125:1467-1471.

40. Dasgupta, P., et al. 2006. Nicotine inhibits apoptosis induced by chemotherapeutic drugs by up-regulating XIAP and survivin. Proc. Natl. Acad. Sci.U. S. A. 103:6332-6337.

41. Buchanan, F.G., et al. 2006. Role of beta-arrestin 1 in the metastatic progression of colorectal cancer. Proc. Natl. Acad. Sci. U. S. A. 103:1492-1497.

42. Ishizawar, R., and Parsons, S.J. 2004. c-Src and cooperating partners in human cancer. Cancer Cell. 6:209-214.

43. Huang, J., Sun, Y., and Huang, X.Y. 2004. Distinct roles for Src tyrosine kinase in beta2-adrenergic receptor signaling to MAPK and in receptor internalization. J. Biol. Chem. 279:21637-21642.

44. Mukherjee, A., et al. 2005. Regulation of Notch signalling by non-visual beta-arrestin. Nat. Cell Biol. 7:1191-1201.

45. Kang, J., et al. 2005. A nuclear function of beta-arrestin 1 in GPCR signaling: regulation of histone acety- lation and gene transcription. Cell. 123:833-847.

46. Beaulieu, J.M., and Caron, M.G. 2005. Beta-arrestin goes nuclear. Cell. 123:755-757.

47. Wang, Y., et al. 2006. Association of beta-arrestin and TRAF6 negatively regulates Toll-like receptor-interleukin 1 receptor signaling. Nat. Immunol. 7:139-147.

48. Fong, A.M., et al. 2002. Defective lymphocyte chemotaxis in beta-arrestin2- and GRK6-deficient mice. Proc. Natl. Acad. Sci. U. S. A. 99:7478-7483.

49. Togho, A., et al. 2003. The stability of the G proteincoupled receptor-beta-arrestin interaction determines the mechanism and functional consequence of ERK activation. J. Biol. Chem. 278:6258-6267.

50. Mai, H., May, W.S., Gao, F., Jin, Z., and Deng, X. 2003. A functional role for nicotine in $\mathrm{Bcl} 2$ phosphorylation and suppression of apoptosis. J. Biol. Chem. 278:1886-1891.

51. Trombino, S., et al. 2004. Alpha7-nicotinic acetylcholine receptors affect growth regulation of human mesothelioma cells: role of mitogen-activated protein kinase pathway. Cancer Res. 64:135-145.

52. Xin, M., and Deng, X. 2005. Nicotine inactivation of the proapoptotic function of Bax through phosphorylation. J. Biol. Chem. 280:10781-10789.

53. Matsushime, H., et al. 1994. D-type cyclin-dependent kinase activity in mammalian cells. Mol. Cell. Biol. 14:2066-2076.

54. Wang, S., Nath, N., Minden, A., and Chellappan, S. 1999. Regulation of Rb and E2F by signal transduction cascades: divergent effects of JNK1 and p38 kinases. EMBOJ. 18:1559-1570.

55. Derossi, D., Joliot, A.H., Chassaing, G., and Prochiantz, A. 1994. The third helix of the Antennapedia homeodomain translocates through biological membranes. J. Biol. Chem. 269:10444-10450.

56. Wang, S., Fusaro, G., Padmanabhan, J., and Chellappan, S.P. 2002. Prohibitin co-localizes with Rb in the nucleus and recruits $\mathrm{N}-\mathrm{CoR}$ and HDAC1 for transcriptional repression. Oncogene. 21:8388-8396.

57. Boyd, K.E., and Farnham, P.J. 1999. Coexamination of site-specific transcription factor binding and promoter activity in living cells. Mol. Cell. Biol. 19:8393-8399.

58. Forsberg, E.C., Downs, K.M., and Bresnick, E.H. 2000. Direct interaction of NF-E2 with hypersensitive site 2 of the beta-globin locus control region in living cells. Blood. 96:334-339. 